\title{
Europe (2018)
}

\author{
Federico Casolari*
}

\section{Developments at EU Level}

\subsection{Towards a Reform of the Union Civil Protection Mechanism}

The most relevant development of European Union (EU) disaster law occurred in 2018 is represented by the provisional agreement reached in December between the European Parliament and the Council of the European Union to revise the Decision establishing the Union Civil Protection Mechanism (hereinafter UCPM or 'Mechanism'). ${ }^{1}$ Such an agreement opens the door to a significant reshaping of the EU cooperation in the civil protection domain, which showed, after some years passed since the Lisbon reform, some major shortcomings. $^{2}$

In November 2017, after a tragic summer characterized by a series of forest fires in Portugal resulting in more than 6o deaths, the European Commission decided to propose the adoption of a new Decision amending the one establishing the Mechanism. ${ }^{3}$ In the Explanatory Memorandum annexed to the Proposal, the European Commission made it clear that the former was proposed in order to fill the gaps stressed by the Interim Evaluation of the $\mathrm{UCPM}^{4}$ and

* Associate Professor of EU Law, Alma Mater Studiorum - University of Bologna.

1 European Commission, 'rescEU: Commission welcomes provisional agreement to strengthen EU civil protection' (2018), available at <https://ec.europa.eu/echo/news/resceu-commission-welcomes-provisional-agreement-strengthen-eu-civil-protection_en $>$ last accessed (as any subsequent URL) on 30 June 2019. The UCPM was established by Decision No 1313/2013 of the European Parliament and of the Council, OJ L347, 20 December 2013, 924. For a general survey of the Mechanism, see Marco Gestri, 'EU Disaster Response Law: Principles and Instruments', in Andrea de Guttry et al (eds), International Disaster Law (T.M.c. Asser Press 2012) 105 .

2 In 2019 the EU Parliament and the Council have adopted the text of the new Decision reshaping the Mechanism. See Decision (EU) 2019/420 of the European Parliament and of the Council of 13 March 2019 amending Decision No 1313/2013/EU on a Union Civil Protection Mechanism, OJ L771, 20 March 2019, 1. That new Decision will be analysed in the next issue of this Yearbook.

3 European Commission, doc. сом(2017) 772, 23 November 2017, final.

4 ICF, 'Interim Evaluation of the Union Civil Protection Mechanism. 2014-2016' (2017), <https:// publications.europa.eu/en/publication-detail/-/publication/eb41bfee-78c3-11e7-b2f2o1aa75ed71a1/language-en/format-PDF>. 
other performance assessments, such as the review from the European Court of Auditors. ${ }^{5}$ The major shortcoming revealed by those assessments, and confirmed by the relevant practice, was identified in the weaknesses of the Union and member States' collective ability to respond to disasters. Large-scale emergencies affecting several member States at the same time revealed indeed the inability of the EU to react to the requests of assistance notified under the Mechanism. On the one hand, this was due to the voluntary nature of member States' contributions to respond to disasters via the UCPM. ${ }^{6}$ On the other, relevant gaps in certain response capacities (such as those deployed in case of forest fires) further limited the effectiveness of the Mechanism, requiring thus a normative intervention at supranational level.

Against this general background, the European Commission's Proposal introduced the possibility to establish a dedicated reserve of response capacities at Union level, with decision on deployment taken by the Commission, which was also in charge of retaining command and control over such capacities (to be known as 'rescEU'). ${ }^{7}$ More precisely, pursuant to article $1(6)$ of the proposed amending Decision, the Commission should have had the power to acquire, rent, lease and/or otherwise contract rescEU capacities to be deployed under the Mechanism. The EU institution was also responsible for defining the required quality of the response capacities and it was requested to ensure their availability and deployability.

Not surprisingly, the Proposal made by the Commission was highly criticized by several member States. It has to be stressed, indeed, that the action put in place by EU institutions under the UCPM is covered by a parallel competence of the Union. Pursuant to article 2(5) TFEU, such competence cannot be exercised by EU institutions to supersede the member States' action in the areas concerned. Moreover, legally binding acts of the Union adopted on the basis of the provisions of the treaties relating to these areas shall not entail harmonization of member States' laws or regulations. In other words, the EU's parallel competences have been understood by the treaties' drafters as domains of cooperation where the Union may only support the action of the member States without replacing them in the management of relevant

5 European Court of Auditors, 'Special Report' (2016), <http://www.eca.europa.eu/Lists/ ECADocuments/SR16_33/SR_DISASTER_RESPONSE_EN.pdf>.

6 According to articles 15 and 16 of the UCPM Decision, '[a]ny Member State to which a request for assistance is addressed through the Union Mechanism shall promptly determine whether it is in a position to render the assistance required (...)'.

7 Other innovations concern the strengthening of the support for member States to improve their disaster risk management. Due to space constraints, this contribution only considers the arrangements related to the creation of rescEU. 
activities. Against this backdrop, the proposed amendments to the UCPM introducing the possibility for the Commission to exercise a 'complete control' on certain reaction capacities without giving the member States a specific role to be played, was (rightly) considered to be in contrast with the inherent nature of the EU competence in the civil protection domain and, ultimately, with the principle of conferral enshrined in the treaties. As a consequence, a negotiation was launched between the Council and the Parliament to ameliorate the Commission's Proposal, eventually leading to the political agreement reached in December 2018.

At the basis of this agreement is the idea that rescEU capacities shall be established to provide assistance in overwhelming situations where overall existing capacities at national level and those pre-committed by member States to the European Emergency Response Capacity ${ }^{8}$ are not able to ensure an effective response. RescEU is thus conceived, in the agreement reached among the two political institutions, as a last resort tool "within the UCPM" and to be triggered only when the other capacities available at national and EU level are not sufficient to deal with the disaster scenario. ${ }^{9}$ Having clarified this, the

8 According to article 11 of the UCPM Decision, the European Emergency Response Capacity consists of voluntary pools of pre-committed response capacities of the Member States and includes modules, other response capacities and experts. The most relevant component of the European Emergency Response Capacity is today represented by the European Medical Corps, officially launched in February 2016 after the Ebola health crisis. In 2018, the European Commission, acknowledging relevant international processes such as the initiative of the World Health Organisation to classify Emergency Medical Teams and the guidelines established by the International Search and Rescue Advisory Group (INSARAG), amended its Implementing Decision 2014/762/EU defining the capacity goals, the quality and interoperability requirements, and the registration and certification procedure of the European Emergency Response Capacity (EERC) as well as the general requirements for civil protection modules, in order to fully include the European Medical Corps into the EERC. See Commission Implementing Decision (EU) 2018/142 of 15 January 2018 amending Implementing Decision 2014/762/EU laying down rules for the implementation of Decision no. 1313/2013/EU of the European Parliament and of the Council on a Union Civil Protection Mechanism, OJ L25, 20 January 2018, 40 .

9 It is important to stress that rescEU is understood as a last resort instrument "within the EU СРM". There are indeed other instruments available at EU level (outside the UCPM) to face disaster scenarios (consider, for instance, the European Solidarity Fund that has been mobilised several times in 2018 to provide financial assistance to Member States affected by disasters). The last resort instrument to be triggered "at EU level" in a disaster scenario is represented by the solidarity clause enshrined in article $222 \mathrm{TFEU}$. This is clarified by article 4(1) of the Council Decision of 24 June 2014 no. 2014/415/EU on the arrangements for the implementation by the Union of the solidarity clause, stating that: 'In the event of a disaster or terrorist attack, the affected Member State may invoke the solidarity clause if, after having exploited the possibilities offered by existing means and tools at national and Union level, it considers 
agreement also sheds some light on the allocation of competences between the member States and the Commission. It is indeed for the member States to acquire, rent or lease rescEU capacities, thereby benefiting from the financial support awarded by the Commission. The capacities are hosted by the member States acquiring, renting or leasing them. Moreover, such States are responsible for directing the response operations (inside the Union) and for ensuring that rescEU capacities are fully integrated into the overall response (outside the Union). As for the Commission, it is in charge of: (a) defining the quality requirements of capacities; (b) deciding their deployment and demobilization; (c) facilitating the coordination of rescEU capacities with other assets deployed under the Mechanism.

As it clearly emerges from those elements, compared to the original Commission's Proposal, the role played by the European Commission in managing rescEU capacities has been significantly limited. Not only has the institution an ancillary position in the acquisition of relevant capacities; it has also been deprived of the possibility to exercise an effective command and control over them. This said, it seems however that the Commission still enjoys a (rather) relevant margin of manoeuvre, which might cause some (further) concerns in the light of the nature of the EU competence exercised to reshape the Mechanism. It is indeed the Commission which is entitled to take the final decision concerning the deployment and demobilization of rescEU capacities. The political agreement reached between the European Parliament and the Council clarifies that such a decision shall be taken 'in close coordination' with the requesting State and the member State owing, renting or leasing the capacities. It is however not clear what such coordination implies in practice and whether member States may pose a veto on the final decision adopted by the Commission. It is possible - and desirable - that some clarifications could come through the implementation decisions (detailing the functioning of rescEU) adopted in the near future by the Commission.

Also importantly, the introduction of rescEU capacities risks producing unnecessary duplication of (and thus a jeopardization of) the assistance that may be rendered available by member States via the UCPM. This is why the implementation decisions adopted by the Commission should also better substantiate the last-resort nature of rescEU capacities vis-à-vis other capacities deployable by member States.

that the crisis clearly overwhelms the response capabilities available to it' (OJ L192, 1 July 2014, 53). See also Ben Smulders and Jean-Paul Keppenne, 'Commentary to Article 222 TFEu', in Hans von der Groeben et al (eds), Europäisches Unionsrecht, vol. 3 (Nomos 2015) 943. 
1.2 EU Defence Cooperation and Disaster Management

As clarified by the UCPM Decision, ${ }^{10}$ the Union action carried out within the Mechanism shall complement - and be consistent with - the other activities put in place by the EU inside and outside its borders to face disaster scenarios. In this respect, it is useful to mention some further developments which occurred in 2018 concerning other strands of EU action which are closely related to the activities put in place under the UCPM.

A first element of practice which deserves to be mentioned is the launch in November of the Permanent Structured Cooperation ('PESCO') project which focused on disaster relief. Introduced by the Lisbon Treaty ${ }^{11}$ and established in December 2017, ${ }^{12}$ PESCO is a normative and institutional framework to strengthen defence cooperation between those EU member States who are capable and willing to do so. ${ }^{13}$ More precisely, PEsco is implemented through the development of specific projects, under the oversight of the Council, that are managed by those member States that take part in it. On 19 November 2018, the Council adopted an updated list of projects to be undertaken under PESCO. 17 new projects have been added to the initial 17 projects agreed on 11 December 2017 and formally adopted on 6 March 2018. ${ }^{14}$ Among them, a Deployable Military Disaster Relief Capability Package has been listed. The Package will be developed by Italy, Greece, Spain, Croatia and Austria and is intended to deliver a multi-national specialist military assistance to EU and other States, which can be deployed within both EU-led and non EU-led operations. The new EU capability will manage a range of emergencies including man-made disasters, civil emergencies, and pandemics. The Project also aims

10 See in particular article 26(2) of the Decision, stating that '[s]ynergies and complementarity shall be sought with other instruments of the Union'.

11 Treaty on the European Union, articles 42(6), 46 and Protocol no. 10.

12 Council Decision (CFSP) 2017/2315 of 11 December 2017 establishing permanent structured cooperation (PESCO) and determining the list of participating member States, OJ L 331, 14 December 2017, 57. For a general overview, see Alberto Miglio, 'A Schengen of Defence? Integrating Existing Clusters of Inter-State Defence Cooperation into the EU Legal Framework', Centre for Studies on Federalism, Policy Paper (July 2017) no. 25, <http://www.csfederaln ismo.it/images/policy_paper/PP25_A.Miglio_Schengen_Defence_Cooperation_EU.pdf $>$.

13 The 25 member States participating in PEsco are: Austria, Belgium, Bulgaria, Czech Republic, Croatia, Cyprus, Estonia, Finland, France, Germany, Greece, Hungary, Italy, Ireland, Latvia, Lithuania, Luxembourg, the Netherlands, Poland, Portugal, Romania, Slovenia, Slovakia, Spain and Sweden.

14 Specific arrangements on the development of PESCO projects have been set up by Council Decision (CFSP) 2018/909 of 25 June 2018 establishing a common set of governance rules for PESCO projects, OJ L 161, 26 June 2018, 37. An updated list of PESCO projects is available here <https://www.consilium.europa.eu/media/39664/table-pesco-projects .pdf $>$. 
at including the establishment of a new EU Disaster Relief Training Centre of Excellence, and ultimately a Disaster Relief Deployable Headquarter. Even though the recourse to military means is considered as a last resort tool (another one!) by the EUCPM Decision, it is recognized that military capacities may constitute an important contribution to disaster response. ${ }^{15}$

\subsection{Tackling Climate Change in the European Union}

The UCPM Decision includes a general policy framework for Union actions on disaster risk prevention, aimed at achieving a higher level of protection and resilience against disasters by preventing or reducing their effects and by fostering a culture of prevention, including due consideration of the likely impacts of climate change and the need for appropriate adaptation action. As previously mentioned, ${ }^{16}$ such dimensions have been further strengthened by the revised Decision agreed in December. ${ }^{17}$ It is thus important to briefly mention the major developments which occurred during 2018 in relation to the fight against climate change. ${ }^{18}$

The main building blocks of the EU climate policy legal framework adopted in 2018 are the following ones. First, the adoption of Directive EU 2018/410 on emission trading has to be mentioned; it reforms the pre-existing legal framework and introduces a lowering of the emission cap by $2.2 \%$ per year after 2021, compared with 1.74\% currently. Moreover, on 17 April 2018 the European Parliament gave its final approval to a Regulation that will determine the national reductions each member State must achieve by 2030 from non-Emission Trading System sectors, such as transport, agriculture, construction and waste management. Member States are free to decide how best to achieve the reductions,

15 See recital no. 19 of the UCPM Decision. See also Federico Casolari, 'The External Dimension of the EU Disaster Response', in Andrea de Guttry et al (n. 1) 129, 138-141.

16 See (n. 7).

17 The amendments to UCPM Decision on disaster risk reduction and prevention include, inter alia, a strengthening of risk management duties of member States (particularly in cases where States frequently request the same type of assistance through the Mechanism for the same type of disaster), and the establishment of a Union Civil Protection Knowledge Network (composed by civil protection and disaster management actors and institutions) managing training programmes on prevention of, preparedness for (and response to) disasters.

18 An assessment of the action played by the Union on the international stage in that domain is present in Elisa Morgera and Kati Kulovesi, "The Role of the EU in Promoting International Standards in the Area of Climate Change' in Inge Govaere and Sara Poli (eds), EU Management of Global Emergencies. Legal Framework for Combating Threats and Crises (Martinus Nijhoff 2014) 311. 
depending on their national circumstances. ${ }^{19}$ National reductions vary according to the level of development and capacity of each country, from zero for Bulgaria and $-2 \%$ for Romania, to cuts in the range of $-38 \%$ to $-40 \%$ for Germany, Denmark, Luxembourg, Finland and Sweden. Also on 17 April 2018 the European Parliament gave its final approval to a Regulation that brings carbon sinks into the EU emissions reduction effort. ${ }^{20}$ Carbon sinks include resources such as forests that can lock in carbon when they are growing or expanding, but release it when they are cut down. Under the Regulation, member States must ensure that, on balance, emissions and removals from carbon sinks are balanced, and that therefore poor management of carbon sinks does not undermine emissions reductions from other sectors.

In conclusion, it is important to note the resolution adopted by the European Parliament in January 2018 on women, gender equality and climate justice. ${ }^{21}$ The Resolution urges the European Commission, together with the member States, to secure a gender-sensitive approach within the climate change related activities they carry out. It stresses the need to ensure a better representation of women in UNFCCC negotiations. In this respect, member States should provide funding for women delegates' training and participation while the Commission should facilitate and support the networking of women's organisations and civil society activities as regards the development and implementation of climate change policies, and ensure that women are equal participants in, and beneficiaries of, all climate change consultations, programmes and funding organised with EU support at national and local levels.

Developments within the Council of Europe

On the European continent other major developments concerning disaster prevention and management have occurred under the umbrella of the Council of Europe ( $\mathrm{CoE})$. As is well-known, a specific platform for co-operation in the field of major natural and technological disasters - EUR-OPA Major Hazards

19 Regulation (EU) 2018/842 of the European Parliament and of the Council of 30 May 2018 on binding annual greenhouse gas emission reductions by member States from 2021 to 2030 contributing to climate action to meet commitments under the Paris Agreement and amending Regulation (EU) No 525/2013, OJ L156, 19 June 2018, 26.

20 Regulation (EU) 2018/841 of the European Parliament and of the Council of 30 May 2018 on the inclusion of greenhouse gas emissions and removals from land use, land use change and forestry in the 2030 climate and energy framework, and amending Regulation (EU) No 525/2013 and Decision No 529/2013/EU, OJ L156, 19 June 2018, 1.

21 OJ C458, 19 December 2018, 34. 
Agreement - has been established among CoE States in $1987 .{ }^{22}$ As in the case of all other activities carried out within the Council of Europe, EUR-OPA achievements have also been significantly undermined by budgetary constraints. Turkey's decision to end its status as a major contributor to the Council of Europe has been followed by its decision to entirely withdraw its EUR-OPA membership from the end of 2018. This decision translates to a loss of EUR 325.000 per year for EUR-OPA's budget from January 2019. ${ }^{23}$ Also, due to divergences between the Russian Federation and the Parliamentary Assembly of the Council of Europe, the Russian Federation has withheld $2 / 3$ of funds in 2017 and all of its in 2018 contribution. ${ }^{24}$

However, despite such difficulties, EUR-OPA cooperation has led to some significant results. Apart from the projects funded by the platform, ${ }^{25} \mathrm{EUR}-\mathrm{OPA}$ supported other relevant activities. EUR-OPA contributed, for instance, to the realization of a two-day international conference organized by the European University Centre for Cultural Heritage on 'Culture Against Disasters - Protecting cultural Landscape as Prevention of Natural Disaster' (28-29 September, Ravello, Italy). ${ }^{26}$ The main aim of the conference consisted of highlighting the role that the conservation of heritage may play as a means to prevent disaster risks. Having in mind the legal framework represented by the European Landscape Convention, ${ }^{27}$ and taking stock of relevant documents elaborated by international organizations (including Council of Europe, UNESCO and ICOMOs), the conclusion was reached that it would be advisable to draft a

22 Notwithstanding its name, EUR-OPA is nothing but a soft-law cooperation forum. See Andrea de Guttry, 'Surveying the Law', in Andrea de Guttry et al (n. 1) 3, 30. In 201826 States were parties to that cooperation.

23 EUR-OPA 2018 budget was of EUR 878.400. See EUR-OPA Major Hazards Agreement, 'Draft budget for 2019' (2018) <https://rm.coe.int/2019-draft-budget-of-the-european-and-medie terranean-major-hazards-agre $/ 16808 \mathrm{~d} 78 \mathrm{c} 4>$.

24 Turkey's decision to limit its financial contribution to the Council of Europe's budget follows the reaction by $\mathrm{CoE}$ bodies to the severe human rights restrictions introduced by that State after the alleged military coup in 2016. As for the Russian Federation, political struggles are related to the reaction by Parliamentary Assembly of the Council of Europe to the occupation of Crimea. See Kanstantsin Dzehtsiarou and Donal K. Coffey, 'Suspension and expulsion of members of the Council of Europe: Difficult decisions in troubled times', (2019) 68 International \& Comparative Law Quarterly, 443.

25 For an updated list of 2018 projects, see EUR-OPA Major Hazards Agreement, 'Joint meeting of the Committee of Permanent Correspondents and Directors of Specialised Centres. Meeting Report 6-7 November 2018' (2018), <https://rm.coe.int/joint-meeting-of-the -committee-of-permanent-correspondents-and-directo/1680901e $77>$.

26 The Conference report may be found at $<$ https://rm.coe.int/report-on-the-international -conference-on-culture-against-disasters-pr/16808 5 c $3 f>$.

27 European Landscape Convention, 20 October 2000. 
comprehensive and pragmatic guidance and strategy document illustrating concrete actions that are needed. This document should be drafted by triggering the methodology enshrined in the Council of Europe Framework Convention on the Value of Cultural Heritage for Society (Faro Convention), ${ }^{28}$ encouraging everyone to participate in the identification, study, interpretation, protection, conservation and presentation of cultural heritage. ${ }^{29}$

EUR-OPA also contributed to the organization of the European Forum for Disaster Risk Reduction (21-23 November 2018) in Rome, which hosted representatives of 20 European countries, relevant international organizations and bodies (such as the World Bank, the United Nations Office for Disaster Risk Reduction, and the European Commission), stakeholders groups and partners. Moving from the commitments assumed under the Sendai Framework for Disaster Risk Reduction 2015-2030, the (rather vague) final communique of the Forum highlights the importance of a whole-of-society approach, 'involv[ing] key stakeholder groups including women, persons living with disability, youth and children, elderly persons, the private sector and civil society in all its diversity' ${ }^{30}$ The document lists, inter alia, the following commitments: (a) establishing and enabling the national and local disaster risk reduction strategies through a system wide approach promoting inclusiveness and resilient investments; (b) ensuring disaster risk assessments as a prerequisite for infrastructure investments; (c) promoting public and private risk informed investments; (d) supporting the disaster risk management and civil protection authorities to better integrate the risks of climate change into risk reduction, prevention, preparedness and response actions.

28 Faro Convention, 27 October 2005.

29 Ibid., art. 12.

3o European Forum for Disaster Risk Reduction, 'High-Level Communiqué of the Chair. Protecting Europe's citizens: the social contract on disaster resilience' $(2018)<$ https://www .preventionweb.net/files/57664_hlcommuniquefinal.pdf>, para. 12. 